\title{
TRANSPORT APPLICATION OF HYBRID SIMULATION
}

Simulation of a road or rail vehicle is a very complex task. There are many possibilities to build the mathematical model according to the goals of the simulation. It can be built either as a general full-editable block model, which will cover all possible structures of the vehicle or as a single-purpose model built for the specific structure and its calculation. Each approach can follow suitable results, but the building and calculating time and work consumption can be incomparable.

Keywords: Transportation, simulation, hybrid mathematical model, vehicle.

\section{Introduction}

Mathematical models of complex transport system (such as vehicle) can be modelled as a combination of time-driven elements (vehicle body and transmission components) and the event-driven elements (automatic transmission controller, driver model).

Event-driven dynamics define the class of Discrete Event Systems (DES). The main difference between time-driven system and event-driven systems is the behaviour of the answer to the independent variable change [1] and [2].

The mathematical models, which use both of the elements, are so called hybrid models (hybrid systems - Fig. 1). It is possible to build them using the appropriate calculation tools and solvers (e. g. Simulink - time-driven elements and Stateflow - event-driven elements).

Stateflow extends Simulink with a discrete-event simulation model of computation.

\section{Road vehicle simulation}

The simulation of a road vehicle can contain many of its components or just a particular part of the complex structure [3]. Generally, the area of the simulation can be understood as an interaction between:

- driver,

- vehicle

- load,

- environment.

\section{DES driver model}

The driver interferes with the vehicle by (Fig. 2) [3] and [4]:

- steering (influences the lateral dynamics),

- accelerator and brake pedals, clutch and gear shifting (influences the longitudinal dynamics of the vehicle).

\section{Event-driven system}

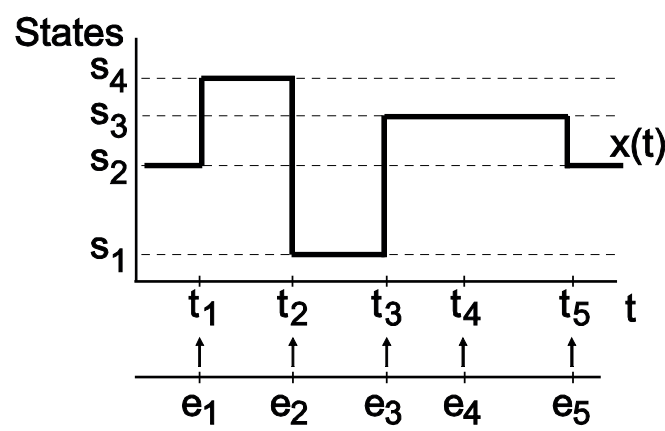

Time-driven system

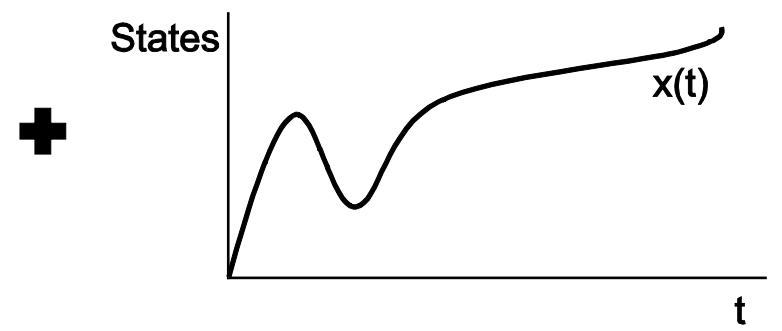

Fig. 1 Structure of the hybrid system (Source: authors)

\footnotetext{
* Frantisek Brumercik, Roman Danko

Mechanical Engineering Faculty, University of Zilina, Slovakia, E-mail: brumercikf@fstroj.uniza.sk Suarez \& Bewarder GmbH \& Co. KG, Gerlingen, Germany
} 
The driver is gathering the information for his driving decisions from:

- vehicle (vibrations, sounds, instruments data),

- environment (climate, traffic density, track).

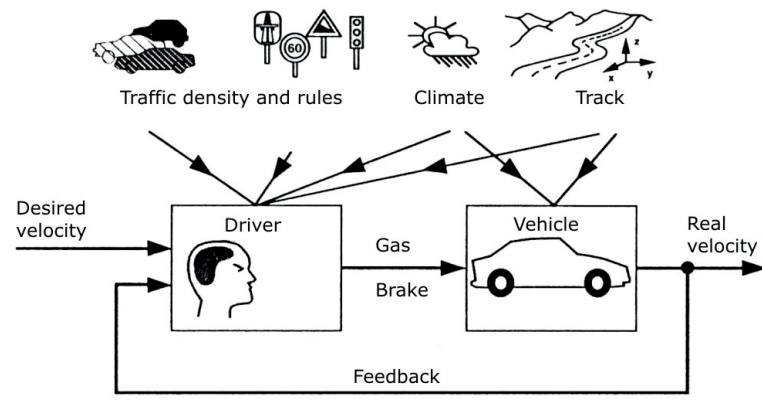

Fig. 2 Interactions between the driver, vehicle and environment (Source: authors)

Many driving manoeuvres require inputs of the driver at the steering wheel and the gas pedal which depend on the actual state of the vehicle. A real driver takes a lot of information provided by the vehicle and the environment into account. He acts anticipatory and adapts his reactions to the dynamics of the particular vehicle. The modelling of human actions and reactions is a challenging task. That is why driving simulators operate with real drivers instead of driver models. However, offline simulations will require a suitable driver model.

The decisions made in the driver model do not lend themselves to well-formulated equations. Thus, it is also much better suited for a Stateflow representation.

The presented Stateflow driver model controls the position of the gas (alpha), clutch (gamma) and brake (beta) pedal and the speed gear inserted (i) according to the required driving manoeuvre, driving strategy and the desired command variable obtained from the time-driven model of the vehicle dynamics.

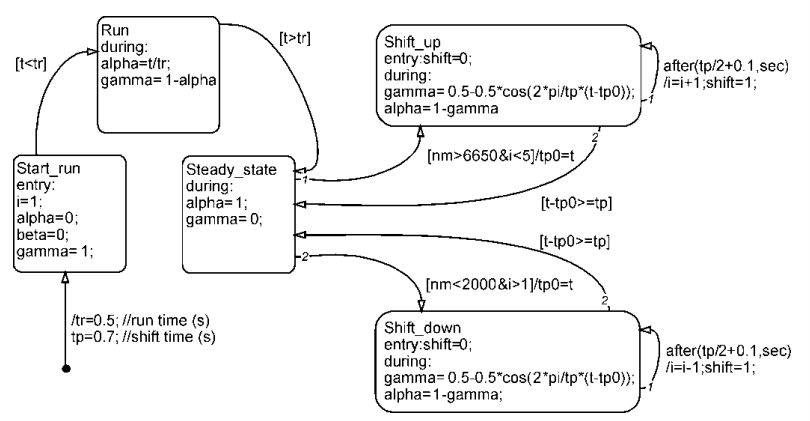

Fig. 3 DES driver Stateflow model structure (Source: authors)

The driver model is very simple according to the desired driving manoeuvre (acceleration to maximum vehicle speed). The input variable is the engine speed value, which has to be maintained within the desired range. If the engine speed exceeds the maximum value, the driver model shifts up. The model also allows the downshifting, but the brake pedal is in the simplest representation non-active [5].

The Stateflow block which implements gear selection for the transmission and the pedals position is shown in Fig. 3.

\subsection{Dynamic vehicle model}

The vehicle has to be depicted in mathematically describable substitute systems for computer calculations. The generation of the equations of motion, the numeric solution as well as the acquisition of the data require great expenses. At an early stage of development often only prototypes are available for field and/ or laboratory tests. The model of a vehicle contains quantum of particular subsystems. The number of the subsystems and their complexity depends on required accuracy of simulation results and the amount of available input data.

Every part of the subsystem can be described by equations that fit the function of the technical system into mathematical model by selected level of simplification.

\subsection{Load model}

The load of the vehicle is mostly represented as a driving resistance in longitudinal direction. The load depends on the vehicle mass, the rolling resistance of the tires, and aerodynamic drag. Then, the simulation is based on motion equations calculated in each simulation step according to possible driving force generated by the vehicle motor and driver decisions affecting the gas and brake pedal (also gear shifting by manual gearboxes) [6].

\subsection{Environment model}

The environment influences driver's decisions by the track profile, the weather conditions (dry, rain, fog, snow - rolling resistance between tire and road), traffic density (free road, traffic jam, stop and go drive) and traffic rules (traffic lights, road signs, overtaking and turn off rules) [6] and [7].

The track can be defined either as a full parallel (two) or simplified 2D data model ( $\mathrm{x}-\mathrm{z}$, Fig. 4), which can be used by longitudinal dynamics calculations, or 3D data model ( $x-y-z$, Fig. 5) that can be used by the longitudinal and lateral dynamics calculation. Both models allow to calculate the vertical dynamics of the vehicle (damping). 
Road profile $z=z(s)$

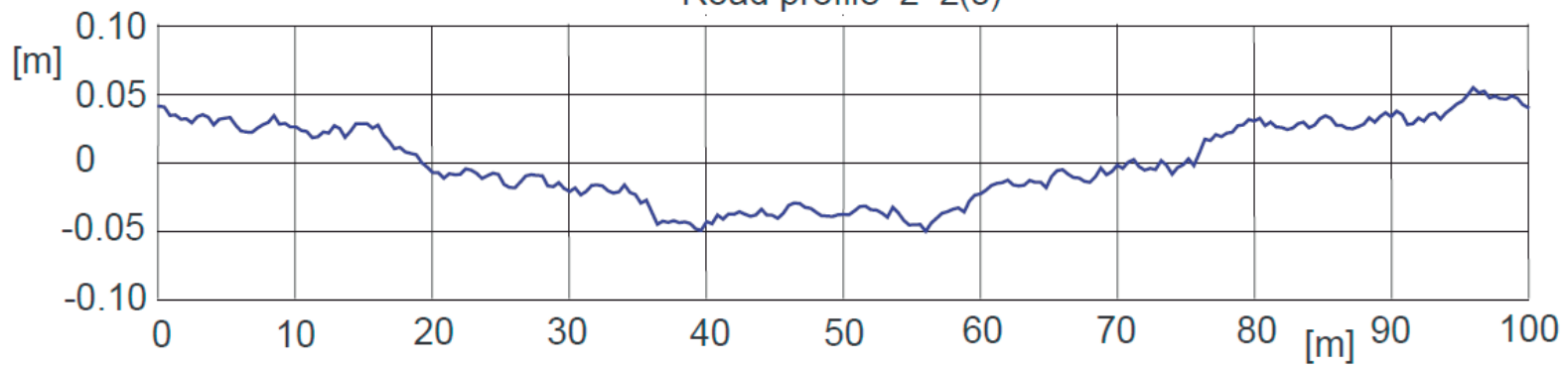

Fig. 4 Vertical road profile example of a simplified centreline track model

(Source: authors)

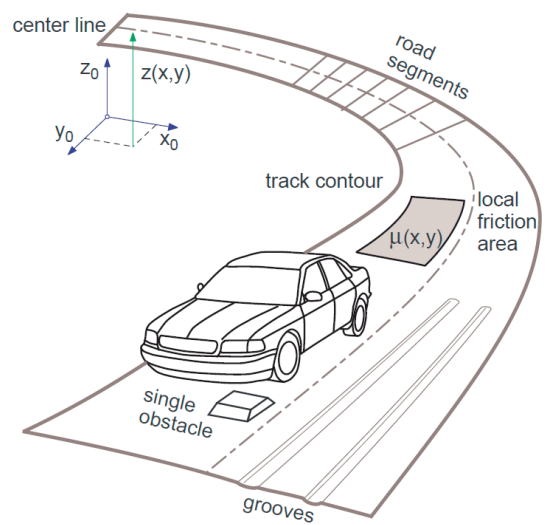

Fig. 5 Complex track model (Source: authors)

\section{Hybrid block model description}

The described hybrid block model example represents the typical road vehicle drivetrain with manual gearbox.

Figure 6 shows the power flow connections (based on torque and speed) in a typical automotive drivetrain block model with manual gearbox. Nonlinear ordinary differential equations model the engine, dry clutch, five-speed manual transmission, non-rigid shafts, differential, vehicle body, wheel and tire in the Simulink environment.

The driver is modeled as DES via Stateflow according to Fig. 3.

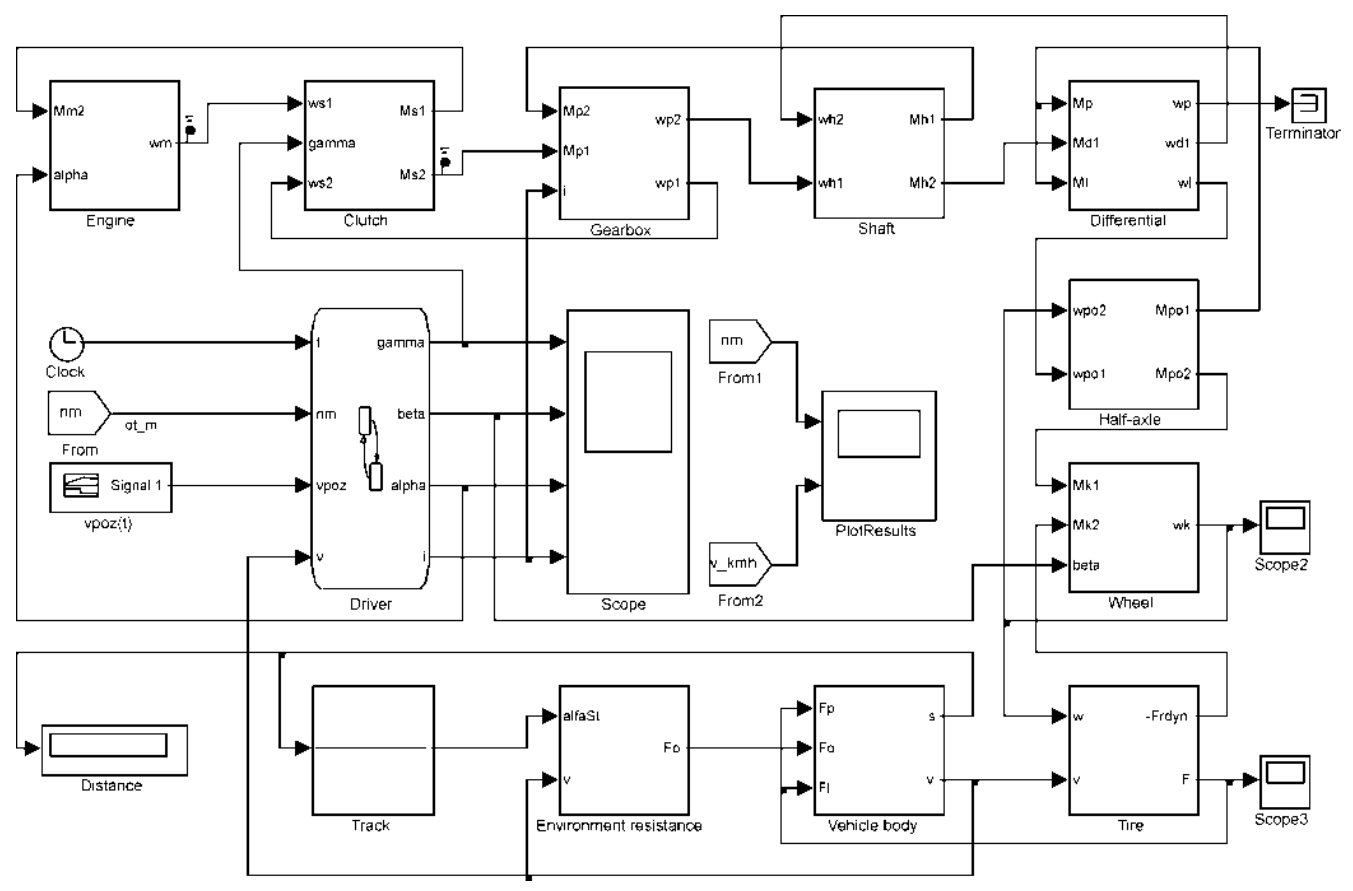

Fig. 6 Vehicle hybrid block model layout (Source: authors) 


\section{Simulation results}

The simulation example of the road vehicle model represents the maximum acceleration manoeuver. The simulation time was defined to 60 seconds. The time behaviour of the selected variables observed during the simulation is shown in Figs. 7, 8 and 9.

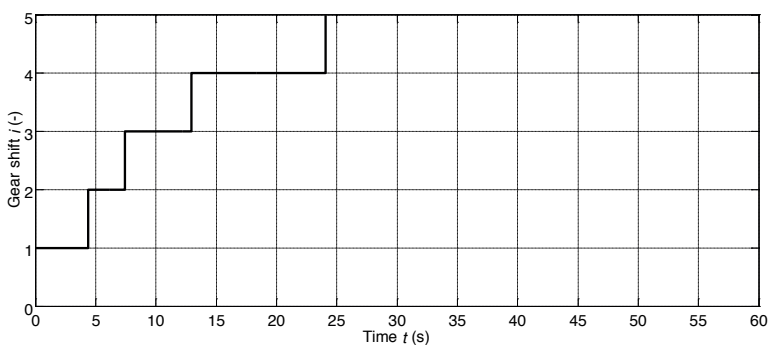

Fig. 7 Gear shift procedure (Source: authors)

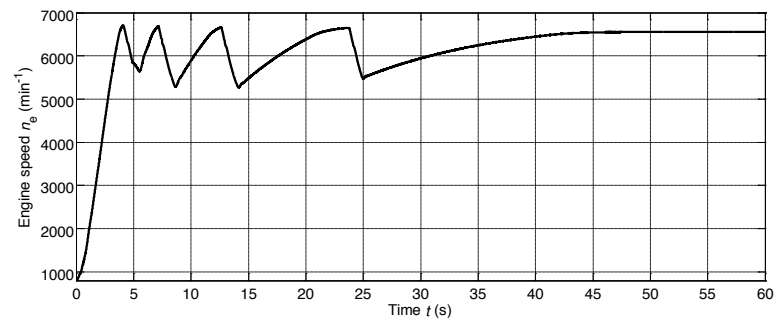

Fig. 8 Engine speed behaviour (Source: authors)

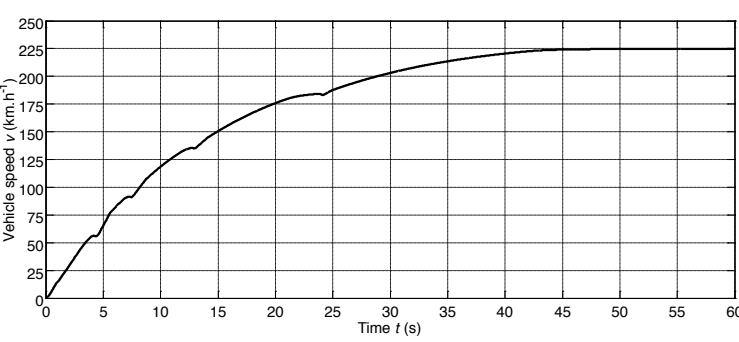

Fig. 9 Progress of the vehicle speed (Source: authors)

The acceleration of the modelled car to maximum speed of $225 \mathrm{~km} \cdot \mathrm{h}^{-1}$ was achieved in $45 \mathrm{~s}$.

\section{Conclusion}

Mathematical modelling and computer aided simulation of technical system virtual prototype behaviour is an important technique that influences the efficiency of the machine design process. It is a procedure, which allows to improve the machine design considerably, including the unconventional transmissions in plenty of applications [7] - [11]. This method requires the knowledge that enables to abstract the technical system into a mathematical model with reasonable level of simplification. Once the correct simulation model is built, there are wide possibilities of parameter changes without excessive demand on working and calculation time.

\section{References}

[1] BRUMERCIK, F.: Transport Applications of Discrete Event System Models, Logi: Scientific J. on Transport and Logistics, vol. 3, No. 2- 2012, pp. 14-20, ISSN 1804-3216.

[2] BRUMERCIK, F.: Discrete Event Simulation of Logistic and Transport Systems, Logi: Scientific J. on Transport and Logistics, vol. 2, No.1-2011, pp. 5-10, ISSN 1804-3216

[3] BRUMERCIK, F., LUKAC, M.: Vehicle Simulation Possibilities, Logi: Scientific J. on Transport and Logistics, vol. 3, No. 1- 2012, pp. 45-52, ISSN 1804-3216.

[4] KUCERA, L., LUKAC, M., JURAK, L., BRUMERCIK, F.: Hydromechanical Automatic Transmission, Communications Scientific Letters of the University of Zilina, vol. 11, No. 2, 2009, pp. 33-35, ISSN 1335-4205.

[5] BRUMERCIK, F.: Simulation of an Unconventional Vehicle Transmission, Logi: Scientific J. on Transport and Logistics, vol. 3, No. 1- 2012, pp. 36-44, ISSN 1804-3216.

[6] BRUMERCIK, F., KOCUR, R., PAZICAN, M., LUKAC, M.: Differential Hydro-mechanical Transmissions with Hydrostatic Units, Communications - Scientific Letters of the University of Zilina, vol. 7, No. 1, 2005, pp. 49-53, ISSN 1335-4205.

[7] KAMPF, R., LIZBETIN, J., LIZBETINOVA, L: Requirements of a Transport System User, Communications - Scientific Letters of the University of Zilina, ISSN 1335-4205, vol. 14, No. 4, 2012, pp. 106-108.

[8] BUKOVA, B., BRUMERCIKOVA, E.: The Role of Innovation in Transport Company, LOGI 2010: 11 $1^{\text {th }}$ Intern. Scientific Conference, Harmony Club Hotel, Pardubice, Brno: Tribun EU, 2010. ISBN 978-80-7399-205-7.

[9] DROZDZIEL, P., KRZYWONOS, L.: The Estimation of the Reliability of the First Daily Diesel Engine Start-up During its Operation in the Vehicle, Eksploatacja i Niezawodnosc - Maintenance and Reliability 1(41), 2009, pp. 4-10, ISSN 1507-2711. 


\section{COMMNICOIIONS}

[10] WU, D., YAO, J., LI, H., QIAN, B.: Control Strategy for Hydro-mechanical Differential Turning System of Tracked Vehicles, Nongye Gongcheng Xuebao / Transactions of the Chinese Society of Agricultural Engineering, vol. 28, No. 8, 2012, pp. 78-83, ISSN 1002-6819.

[11] WANG, G., ZHU, S., SHI, L., TAO, H., VANTHINH, N.: Experimental Optimization on Shift Control of Hydraulic Mechanical Continuously Variable Transmission for Tractor, Nongye Gongcheng Xuebao / Transactions of the Chinese Society of Agricultural Engineering, vol. 29, No. 18, pp. 51-59, 2013, ISSN 1002-6819. 